\title{
ANTIOXIDANT ENZYME ACTIVITIES AND LIPID PEROXIDATION IN PATIENTS WITH BIPOLAR AFFECTIVE DISORDER
}

\author{
Raju Kumar Dubey ${ }^{1}$, Narayan Gautam ${ }^{2}$, Niraj Dhakal ${ }^{3}$, Nirmal Baral ${ }^{4}$, Madhab Lamsal ${ }^{4}$ Pramod M Shyangwa ${ }^{5}$,
}

\section{ABSTRACT}

INTRODUCTION: Brain is particularly vulnerable to oxidative free radicals. Oxidative stress might primarily or secondarily be involved in the pathogenesis of Bipolar Affective Disorder. Therefore this study was aimed to estimate \& compare parameters of oxidative stress and antioxidant levels in patients with Bipolar Affective Disorder and healthy controls.

MATERIALAND METHODS: A total of 32 Bipolar Affective Disorder patients and 30 healthy subjects were recruited in this study. Plasma MDA level was measured as indicator of lipid peroxidation and SOD and CAT activities were determined as a measure of antioxidant status.

RESULT: Out of total Bipolar Affective Disorder patients 21 were in mania with psychotic symptoms, 8 were in mania without psychotic symptoms and only 3 were in mixed episode. Significantly $(\mathrm{p}<0.001)$ elevated MDA level $(\mathrm{nmol} / \mathrm{ml})$ was found in before treatment patient group (7.11 \pm 1.62$)$ as compared to control (3.02 \pm 1.30$)$ group. Patients on followup also had significantly increased MDA level $(\mathrm{nmol} / \mathrm{ml})(5.37 \pm 1.36)$ as compared to control group and decrease in level was significant $(\mathrm{p}<0.001)$ in comparison to before treatment patients. CAT and SOD activities $(\mathrm{U} / \mathrm{gm} \mathrm{Hb})$ were significantly decreased in both before treatment $(87.57 \pm 28.79 \& 1341 \pm 167.18)$ and after treatment $(77.12 \pm 29.48 \&$ $1305.56 \pm 154.86)$ patients group compared to the control $(155.92 \pm 29.43 \& 1408.14 \pm 78.82)$ group respectively. CAT and MDA were negatively correlated in the before treatment patients group $(\mathrm{r}=-0.356, \mathrm{p}<0.05)$.

CONCLUSION: The findings suggest that there is increased oxidative stress in Bipolar Affective Disorder patients in comparison to controls.

KEYWORDS: Bipolar Affective Disorder; Catalase; Lithium; Oxidative stress; Super oxide dismutase

1. Assistant Professor, Department of Biochemistry, Universal College of Medical Sciences \& Teaching Hospital, Bhairahawa, Nepal

2. Associate Professor, Department of Biochemistry, Universal College of Medical Sciences \& Teaching Hospital, Bhairahawa, Nepal

3. Clinical Biochemist, National Reference Laboratory (NRL), Pokhara, Nepal

4. Professor, Department of Biochemistry, B. P. Koirala Institute of Health Sciences, Dharan, Nepal

5. Professor, Department of Psychiatry, B. P. Koirala Institute of Health Sciences, Dharan, Nepal

\author{
For Correspondence \\ Dr. Madhab Lamsal, \\ Professor, \\ Department of Biochemistry, \\ B. P. Koirala Institute of Health Sciences, Dharan, Nepal \\ E-mail: lamsalm@gmail.com
}




\section{INTRODUCTION}

Bipolar Affective Disorder (BPAD) is a severe, chronic, and highly disabling psychiatric disorder which is estimated to affect $1 \%$ of the world population. ${ }^{1}$ Although several hypotheses have been postulated including a role for monoamines, gamma amino butyric acid, glutamate and second messenger signaling pathways to reveal the neurochemical mechanisms underlying the pathophysiology of BPAD, more recently oxidative stress has been implicated and there is evidence accumulating to support to its' role. ${ }^{2}$

Under physiological conditions there is a balance between oxidative and antioxidative systems in the organism. Oxidative stress is the imbalance between these systems in favor of the former and has been implicated in the pathophysiology of several neuropsychiatric diseases, including BPAD. ${ }^{3}$ Oxidative stress, due either to increased free radical production and/or inefficient antioxidant systems, leads to lipid peroxidation. ${ }^{4}$ Malonaldialdehyde (MDA), an end-product of lipid peroxidation, is one of the most extensively studied indices of lipid peroxidation and thus oxidative stress.

Antioxidant defense system comprises a series of enzymatic and non-enzymatic components. Super oxide dismutase (SOD), catalase (CAT) and glutathione peroxidase (GPx) are critical antioxidant enzymes that act cooperatively at different sites in the metabolic pathway of free radicals, and altered activity of one of the enzymes without compensatory changes in the other enzymes may result in oxidative stress. Therefore, in the present study we aimed at determining and comparing oxidative damage (via determination of MDA) and antioxidant enzymes (SOD \& CAT) activity levels in patients with BPAD and healthy controls.

\section{MATERIALAND METHODS}

This prospective cross-sectional study was conducted at the Departments of Biochemistry and Psychiatry, B. P. Koirala Institute of Health Sciences, Dharan. 32 diagnosed cases of BPAD, aged 15-50 years, and who were experiencing an acute mood episode, were included in the study. Patients with substance abuse or dependence in the past year or with other psychiatric, neurological disorders and serious medical conditions were excluded. All the patients [before treatment (BT) group; not taking any kind of mood stabilizers and/or antioxidant agent like vitamin $\mathrm{C}$ and Vitamin E] were followed after being treated with mood stabilizers like lithium and/or others at least for six weeks [classified as after treatment group (AT)]. The control group comprised 30 healthy individuals matched for age, sex, dietary and exercising habits. In addition controls did not have a history of any kind of mental disorders in their first degree relatives.

Venous blood samples were processed to obtain plasma and haemolysate. Plasma MDA levels were measured by the thiobarbituric acid method which was modified from the methods of Yagi. ${ }^{5}$ CAT activity was determined by acid dichromate method ${ }^{6}$ and SOD activity was measured by the method of Kakkar.

\section{Statistical analysis}

Data were analyzed using SPSS version 16.0. Statistical evaluations were performed by using t-test and Pearson correlation coefficient. Differences at $\mathrm{p}<0.05$ level were considered to be statistically significant.

\section{RESULTS}

Results are summarized in Table 1 and Figures 1-3. Out of total BPAD patients, 22 patients had no positive family history where as 10 patients had positive family history of some kind of mental illness. Similarly 21 patients were in mania with psychotic symptoms, 8 patients were in mania without psychotic symptoms and only 3 patients were in mixed episode.

Table1 Shows the general characteristics of patients and controls. The mean age(yrs) $(26.03 \pm 7.58)$, height $(\mathrm{cm})$ $(162 \pm 6.5)$ and weight $(\mathrm{kg})(54 \pm 6.85)$ of patients' were compared to that of controls' age $(27.80 \pm 5.11)$, height $(164 \pm 4.6)$ and weight $(56 \pm 6.1)$ respectively $(\mathrm{p}>0.05)$. There were 20 males and 12 females in patients group and 20 males and 10 females in controls group.

Table1: General characteristics of patients and controls

\begin{tabular}{|c|l|l|l|}
\hline Variables & Control $(\mathbf{n}=\mathbf{3 0})$ & Patient $(\mathbf{n}=\mathbf{3 2})$ & P value \\
\hline $\begin{array}{c}\text { Sex } \\
\text { Male } \\
\text { female }\end{array}$ & $20(67 \%)$ & $20(63 \%)$ & \\
\hline Age(yrs)* & $27.80 \pm 5.11$ & $26.03 \pm 7.58$ & 0.11 \\
\hline Weight $(\mathrm{kg})^{*}$ & $54 \pm 6.85$ & $56 \pm 6.1$ & 0.21 \\
\hline Height $(\mathrm{cm}) *$ & $164 \pm 4.6$ & $162 \pm 6.5$ & 0.09 \\
\hline
\end{tabular}

*Values are given as mean $\pm \mathrm{SD}$ 


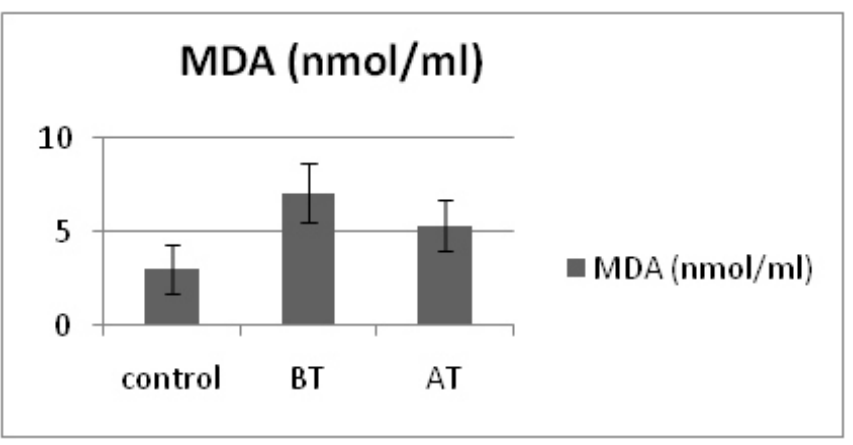

Figure 1: MDA levels in the Controls, BT and AT group

Higher MDA (nmol/ml) levels were observed in both BT (7.11 $\pm 1.62)$ and AT $(5.37 \pm 1.36)$ patient groups compared to the control (3.02 \pm 1.30$)$ group $(\mathrm{p}<0.001$ and $\mathrm{p}<0.001$ respectively).

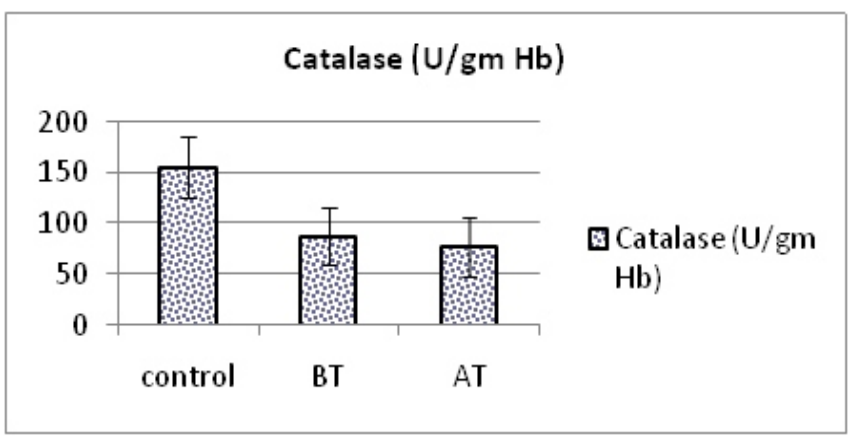

Figure 2: CAT activity in the erythrocytes of the Controls, $B T$ and $A T$ group

There was a significant decrease in erythrocyte CAT (U/gm $\mathrm{Hb})$ activities in the BT (87.57 \pm 28.79$)$ and AT (77.12 \pm 29.48$)$ patient groups compared to control group (155.92 \pm 29.43$)$ ( $\mathrm{p}<0.001$ and $\mathrm{p}<0.001$ respectively).

Figure 3: SOD activity in the erythrocytes of the Controls, $B T$ and $A T$ group

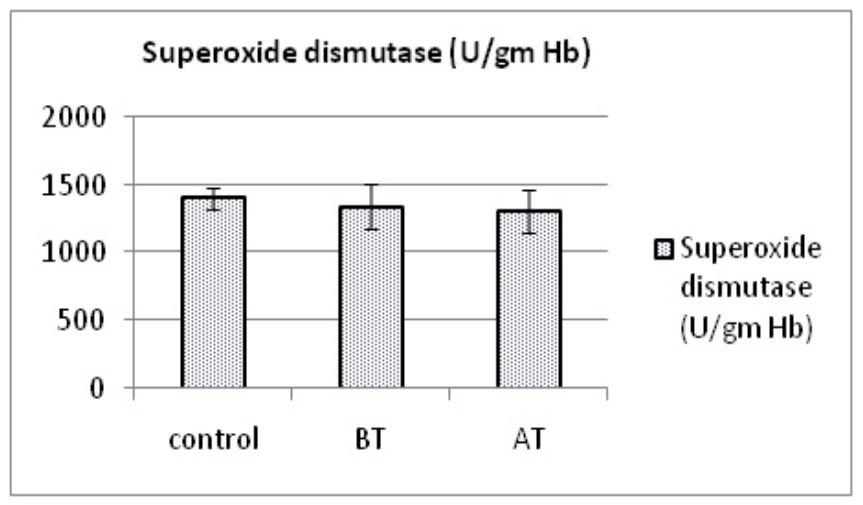

SOD activity $(\mathrm{U} / \mathrm{gmHb})$ was significantly higher $(\mathrm{p}<0.005)$ in the BT $(1341 \pm 167.18)$ patient group compared to AT $(1305.56 \pm 154.86)$ patient group. Similarly these values differed significantly when compared to SOD activity $(1408.14 \pm 78.82 \mathrm{U} / \mathrm{gm} \mathrm{Hb})$ of control group $(\mathrm{p}<0.005$ and $\mathrm{p}<0.002$ respectively).

CAT and MDA were and negatively correlated $(r=-0.356)$ in the BT group $(\mathrm{p}<0.05)$. Similarly we found negative correlation between CAT and SOD $(r=-387)$ in AT group $(\mathrm{p}<0.05)$.

\section{DISCUSSION}

The brain is vulnerable to reactive oxygen species (ROS) production because it metabolizes $20 \%$ of total body oxygen and contains large amounts of iron and polyunsaturated fatty acids. In addition, the brain is relatively poor with respect to antioxidants such as CAT. ${ }^{8,9}$ The present study has highlighted the alteration of SOD \& CAT activity with lipid peroxidation marker MDA in patient with BPAD before and after treatment with mood stabilizer.

In the present study the patient groups had significantly higher MDA level. MDA level decreased significantly after treatment although the value was still higher than the controls. Increased MDA levels disable cellular membrane function by stimulating phospholipase- $\mathrm{A}_{2}$ and thus release interleukins by stimulating the immune system. ${ }^{10}$ The majority of patients $(21$ out of 32) were experiencing severe acute manic episode with psychotic symptoms. Increased MDA levels in patients compared to control group suggests that there is increased lipid peroxidation and oxidative stress during an acute manic episode in patient of BPAD.

To find the level of activities of the free radical scavenging enzymes in patients with BPAD, we preferred red blood cells because these enzymes are constitutively expressed in immature erythrocytes and are easy to obtain. We found lower level of erythrocytes CAT activity, lower level of SOD activity. Erythrocyte CAT and SOD activities were significantly lower in the BT than in the AT patient group. There have been many experimental and clinical treatment studies to investigate the effect of psychotropic medications on antioxidant enzyme activities. The results of these studies are inconsistent. In a study using the olfactory-bulbectomized rat model of depression, CAT and Gpx activities were decreased, while SOD activity was significantly increased. ${ }^{11}$ Similarly another clinical study reported that manicdepressive patients treated with lithium alone or with a combination of lithium and antipsychotics showed increased SOD activities that were approximately $40 \%$ higher than those of normal subjects. ${ }^{12}$ 
Increased production of ROS might be due to impaired catecholamine metabolism, or to the other possible mechanisms in affective disorders. Increased production of ROS might lead to decreased phospholipid amount in the membranes of erythrocytes and to increased MDA levels in erythrocytes. ROS is highly reactive, and they can initiate disruptive peroxidation reactions with various substrates that are important to the survival of cells, such as proteins, lipids and nucleic acids. Neurones are especially vulnerable to free radical attack and impaired defences or exposure to excess free radicals can lead to neuronal death. ${ }^{13}$

A growing body of data shows that many medications and electroconvulsive therapy, which are used for patients with affective disorders, have a substantial effect on the molecular targets that improve mood via neuroprotective mechanisms. Lithium has major effects on bcl-2, as well as on GSK-3b (glycogen synthase kinase-3b), demonstrating that lithium exerts long-term neurotrophic/neuroprotective effects both in vitro and in vivo. ${ }^{14}$ Mood stabilizers (lithium and valproic acid) as well as some antidepressants and electroconvulsive therapy, have recently been shown to activate interconnected intracellular signalling pathways that promote neurogenesis and synaptic plasticity. ${ }^{15}$ Effect of lithium therapy on nonenzymatic antioxidant has recently been shown to improve the status of vitamin $\mathrm{E}$, vitamin $\mathrm{C}$ and glutathione in patients with BPAD. ${ }^{16}$

\section{CONCLUSION}

High MDA and low SOD \& CAT levels suggest that there is increased lipid peroxidation and oxidative stress during an acute mood episode in patients with affective disorders. Therefore, supplementation of the treatment regimen with antioxidant drugs may help in the better outcome for these patients. Future studies should include larger samples to investigate whether there is any difference in the antioxidant enzyme profile in patients with affective disorders who are treated with mood stabilizers alone versus a combination of mood stabilizers and antioxidant agents.

\section{CONFLICT OF INTEREST}

There is no conflict of interest among authors and no compelling interest exists.

\section{ACKNOWLEDGEMENTS}

The authors would like to express sincere thank to the Prof. Shanker Majhi and Mr. Binod Kumar Lal Das (Assistant Prof.), Department of Biochemistry for their constant encouragement and suggestions to carry out of our research work. Authors are also indebted to all the participants and staffs of OPD \& wards of Psychiatry Department, B.P. Koirala Institute of Health Sciences, Dharan, Nepal.

\section{REFERENCES}

1. Belmaker RH. Medical progress: bipolar disorder. NEngl JMed 2004; 351:476-86.

http://dx.doi.org/10.1056/NEJMra035354, PMid:15282355

2. Andreazza AC, Cassini C, Rosa RA, Leite MC, de Almeida LM, Nardin P, et al. Serum S100B and antioxidant enzymes in bipolar patients. JPsychiatry Res 2007; 41:523-29.

http://dx.doi.org/10.1016/j.jpsychires.2006.07.013

PMid:16956621

3. Sies H. Oxidative: from basic research to clinical application. Am JMed 1991; 91:31S-38S.

http://dx.doi.org/10.1016/0002-9343(91)90281-2

4. Adam-Vizi V, Chinopoulos C. Bioenergetics and the formation of mitochondrial reactive oxygen species. Trends Pharmacol Sci 2006; 27:639-45

http://dx.doi.org/10.1016/j.tips.2006.10.005

PMid:17056127

5. Yagi K. Lipid peroxides and human diseases. Chem Phys Lipids 1987; 45:337-51 http://dx.doi.org/10.1016/0009-3084(87)90071-5

6. Sinha AK. Colorimeter Assay of Catalase. Anal Biochem 1972;47:389-94.

http://dx.doi.org/10.1016/0003-2697(72)90132-7

7. Kakkar P, Das B and Vishwanathan PN. A modified spectrophotometric assay of superoxide dismutase. Indian $J$ Biochem Biophys 1984;21:130-32. PMid:6490072

8. Halliwell B, Gutteridge JMC. Oxygen free radicals and iron in relation to biology and medicine: some problems and concepts. Arch Biochem Biophys 1986; 246:501-14. http://dx.doi.org/10.1016/0003-9861(86)90305-X

9. Halliwell B. Oxidants and the central nervous system: some fundamental questions. Acta Neurol Scand 1989; 126:23-33. http://dx.doi.org/10.1111/j.1600-0404.1989.tb01779.x

10. Sierra HMR, Murphy PA. Suppression of interleukin-1 action by phospholipase A2 inhibitors in helper T lymphocytes. Peptide Res 1992; 5:258-61.

11. Song C, Killeen AA, Leonard BE. Catalase, superoxide dismutase and glutathione peroxidase activity in neutrophils of sham-operated and olfactorybulbectomised rats following chronic treatment with desipramine and lithium chloride. 
Neuropsychobiology 1994; 30:2428.

http://dx.doi.org/10.1159/000119131, PMid:7969855

12. Abdalla DS, Manteiro HP, Oliveira JA, Bechara EJ. Activities of superoxide dismutase and glutathione peroxidase in schizophrenic and manic-depressive patients. Clin Chem 1986; 32:805-07. PMid:2870827

13. Jesberger JA, Richardson JS. Oxygen free radicals and brain dysfunction. Int JNeurosci 1991; 57(1-2):117.

http://dx.doi.org/10.3109/00207459109150342, PMid:1938149

14. Manji HK, Quiroz JA, Sporn J, Payne JL, Denicoff K, A Gray N, et al. Enhancing neuronal plasticity and cellular resilience to develop novel, improved therapeutics for difficult-to-treat depression. Biol Psychiatry 2003; 53:70742.

http://dx.doi.org/10.1016/S0006-3223(03)00117-3
15. Coyle JT, Duman RS. Finding the intracellular signaling pathways affected by mood disorder treatments. Neuron 2003; 38:15760. http://dx.doi.org/10.1016/S0896-6273(03)00195-8

16. Dubey RK, Khan SA, Neupane Y, Shyangwa PM, Baral N, Lamsal M. Effect of lithium therapy on non-enzymatic antioxidants in patients with bipolar affective disorder. Int $J$ Pharma Bio Sci 2013;3(3):278-84. 